\title{
Effect of ethanolic leaf extract of noni (morinda citrifolia I.) on blood pressure in ovariectomized rats fed with high-fat diet
}

\begin{abstract}
Menopause has been associated with cardiovascular disease (CVD) complications including hypertension, and stroke. Oestrogen withdrawal and consumption of highfat diet have been related to detrimental effects on cardiovascular function and blood pressure in menopausal women. Hence, the present study was aimed to investigate the effect of Noni (Morinda citrifolia L.) on blood pressure in menopausal rat model fed with high-fat diet. Twenty four Sprague-Dawley rats were randomly divided into four groups; Group 1: Sham control (Sham); Group 2: ovariectomized rats fed with $2 \%$ cholesterol diet (Ovx control); Group 3: ovariectomized rats fed with $2 \%$ cholesterol diet and Noni (125mg/kg/b.w) (Ovx + Noni); Group 4: ovariectomized rats fed with $2 \%$ cholesterol diet and statin $(10 \mathrm{mg} / \mathrm{kg} / \mathrm{b} . \mathrm{w})(\mathrm{Ovx}+\mathrm{Statin})$ daily for eight weeks. Food intake was measured at weekly basis. Body weight and blood pressure (systolic, diastolic and mean) were determined at base line and eighth week respectively. Ovx control and experimental groups showed significant increase in body weight and food intake at eighth week when compared to base line groups. However, there was no significant difference among the experimental treated groups. There was no significant difference in systolic, diastolic and mean blood pressure observed in Ovx control and experimental groups. Based on the above findings, it is believed that Noni did not show any positive effects in ovariectomized rats fed on high-fat diet for eight weeks (short term) to ovariectomized rats fed with high-fat diet resulted in significant increase in the food intake and body weight compared to base line, however there was no significant difference in the blood pressure of Ovx and experimental groups due to short duration of the study.
\end{abstract}

Keywords: morinda citrifolia, high-fat diet, ovariectomized, body weight, blood pressure
Volume I Issue 3 - 2017

\author{
Kumeshini Sukalingam,' Muhammad Zaid \\ Zainuddin,' Gloria Chong,' Norhayati Aida, ${ }^{2}$ \\ Nurul Aina Abdullah, ${ }^{2}$ Faizah Othman' \\ 'Department of Anatomy, University Kebangsaan Malaysia, \\ Malaysia \\ ${ }^{2}$ Department of Pharmacology, University Kebangsaan Malaysia, \\ Malaysia
}

Correspondence: Faizah Othman, Department of Anatomy, Faculty of Medicine, University Kebangsaan Malaysia, Jalan Yaacob Latif, Bandar Tun Razak, 56000 Cheras, Kuala Lumpur, Malaysia, Tel+603-9l45 8637, Email faizahman@gmail.com

Received: July 27, 2017 | Published: August 15, 2017

\section{Introduction}

Cardiovascular disease (CVD) remains as the number one killer of the society worldwide. In $2008,30 \%$ of all global deaths were attributed to CVD. Cardiovascular death has increased at a fast rate in both low and middle-income countries. ${ }^{1}$ There are various causes of CVD among which is menopause, which is greatly related to CVD and its complications, including hypertension, myocardial infarction, stroke, and renal failure. ${ }^{2,3}$ Postmenopausal obesity is also accounted for the increased risk of various diseases, including diabetes, hypertension, osteoporosis and a variety of cancers. ${ }^{2}$ Experimental studies have shown ovariectomized (Ovx) rats as a menopausal model for the tentative investigations. ${ }^{3}$ Elevated blood pressure (BP) is the main symptom in the CVD and is a primary basis of morbidity and mortality worldwide. Hypertension is an intricate disease, with multifactorial disorders including hereditary and lifestyle changes. ${ }^{3}$ Based on the epidemiological surveys, multifactorial conditions are connected with an elevated BP, which includes age, gender, race, diet, consumption of alcohol, physical activity, body weight, socioeconomic status, and emotional disturbances. In Malaysia, the information from Institute of Public Health (IPH) accounted to about $37 \%$ of the inhabitants having hypertension. ${ }^{4}$ Lacking or absence of oestrogens easily causes overweight or obesity after menopause and lacking of physical exercise is one of the primary modulators of this body weight gain. ${ }^{5,6}$ Morinda citrifolia L., or Noni, is a plant belonging to the family Rubiaceae, native to Southeast Asia. Each part of the plant, from its roots to its seeds, is widely used in folk medicine, and several therapeutic effects have already been reported. ${ }^{7}$ Biological actions of $M$. citrifolia include antioxidant ${ }^{8}$ immunostimulatory, ${ }^{9}$ antitumor, ${ }^{10}$ antidiabetic, ${ }^{11}$ anti-obesity ${ }^{12}$ antibacterial and anti-septic, ${ }^{13,14}$ antifungal,,${ }^{15}$ antiviral, ${ }^{16}$ leishmanicidal, ${ }^{17}$ anti-inflammatory, ${ }^{18}$ antinociceptive and analgesic, ${ }^{19}$ neuroprotective, ${ }^{20}$ wound healing, ${ }^{21}$ anti-allergic, ${ }^{22}$ antiangiogenic, ${ }^{23}$ antiemetic and anti-nausea, ${ }^{24}$ anti-gastric ulcer and oesophagitis, ${ }^{25}$ anthelmintic, ${ }^{26}$ antimutagenic, ${ }^{27}$ antipsychotic ${ }^{28}$ anxiolytic, ${ }^{29}$ photo protective, ${ }^{30}$ anti-wrinkle ${ }^{31}$ and periodontal tissue regeneration activities ${ }^{32}$ have been reported. In the present study, we hypothesized the beneficial effect of Noni (Morinda citrifolia L.) in reducing blood pressure in ovariectomized rats fed with high-fat diet.

\section{Materials and methods}

\section{Animals}

This study was performed after obtaining ethical approval from the University Kebangsaan Malaysia Animal Ethics Committees (FP/ ANAT/2014/FAIZAH). Twenty-four adult female Sprague Dawley rats (weighing 250-260g) were used for the present study. All rats had free access to drinking water and fed on the high-fat chow except for the sham group. The animals were allowed to acclimatize for 1 week before the experiment was performed. Throughout the study, the rats were housed one per cage, kept under controlled environmental conditions (12-hour cycle- light/dark) and provided free access to 
food and water ad libitum. Two percent cholesterol diet was purchased from Next Gene Scientific Sdn Bhd, Singapore.

\section{Preparation of M. citrifolia}

Leaves of $M$. citrifolia were obtained from Forest Research Institute Malaysia (FRIM) and botanical identification was done by the taxonomical expert. The leaves were weighed and dried in room temperature, while shaded with no light. The dried leaves were ground to powdered form. The powder was soaked in $70 \%$ ethanol for 3 days. The procedure was repeated twice. It was then filtered and put into a rotatory evaporator. Water was added to form aqueous solution and finally freeze dried to form powder. The extract was administered daily at a dose of $125 \mathrm{mg} / \mathrm{kg} / \mathrm{b}$.w to the respective treatment groups via oral gavage for 8 weeks.

\section{Procedure for ovariectomy}

All the animals, except Sham group were ovariectomized following intraperitoneal injection of ketamine hydrochloride and xylazine (50 and $10 \mathrm{mg} / \mathrm{kg}$ bw respectively). Bilateral ovariectomies were performed from the dorsal approach.

\section{Experimental design}

Animals were divided into four groups with six rats each. All groups were ovariectomized except for sham after being anesthetized with ketamine hydrochloride and xylazine at respective doses of 50 and $10 \mathrm{mg} / \mathrm{kg}$ b.w/i.p once before the ovariectomy procedure. Duration of the feeding was eight weeks.

i. Group 1: Sham fed with Normal rat chow control (Sham);

ii. Group 2: ovariectomized rats fed with $2 \%$ cholesterol diet (Ovx control);

iii. Group 3: ovariectomized rats fed with $2 \%$ cholesterol diet and Noni $(125 \mathrm{mg} / \mathrm{kg} / \mathrm{b} . w)(\mathrm{Ovx}+\mathrm{Noni})$

iv. Group 4: ovariectomized rats fed with $2 \%$ cholesterol diet and statin $(10 \mathrm{mg} / \mathrm{kg} / \mathrm{b} . \mathrm{w})(\mathrm{Ovx}+\mathrm{Statin})$.

\section{Measurement of food intake and body weight}

Food intake and body weight were measured at weekly intervals for four weeks in all the groups. Measurement of food intake was calculated by subtracting the total amount provided to the remaining amounts in the cage. Body weight was measured by using the electronic weighing scale. The increase in the body weight was calculated by deducting the initial weight from the final weight.

\section{Measurement of blood pressure}

Blood pressure was measured using the non-invasive tail-cuff method with sphygmomanometer technique using CODA data during baseline and at the end of eighth week. The rats were anesthetized by inhalation of diethyl ether before the measurement was taken. The readings were measured thrice; one after the other and the mean was then taken as an ultimate reading for systolic BP. The experiment lasted for eight weeks. The systolic, diastolic and mean blood pressure was determined once in a week.

\section{Statistical analysis}

The results were expressed as the mean \pm SD. Statistical analysis, including analysis of variance (ANOVA), was performed using SPSS 20 software. Significant differences $(p<0.05)$ between the means were determined by Duncan's multiple range test (DMRT).

\section{Results}

In the present study, the changes in the body weight and food intake of the animals with consumption of $2 \%$ cholesterol diet, Noni, and Statin were determined (Figure $1 \& 2$ ). The food intake between Ovx control and experimental and Sham groups were compared. It was shown that Ovx group had a significant $(p<0.05)$ increase in food intake at the third and eighth week of the study compared to the Noni and Statin treated groups $(\mathrm{p}<0.001)$. There was no significant difference in food intake between Noni and Statin treated groups, neither with the Ovx control nor with the Sham groups. Furthermore, there was no significant difference in body weights found between Ovx control and Sham groups too. There was a significant $(\mathrm{p}<0.05)$ body weight increase in the Ovx control, Noni and Statin groups at the eighth week when compared to their base line values.

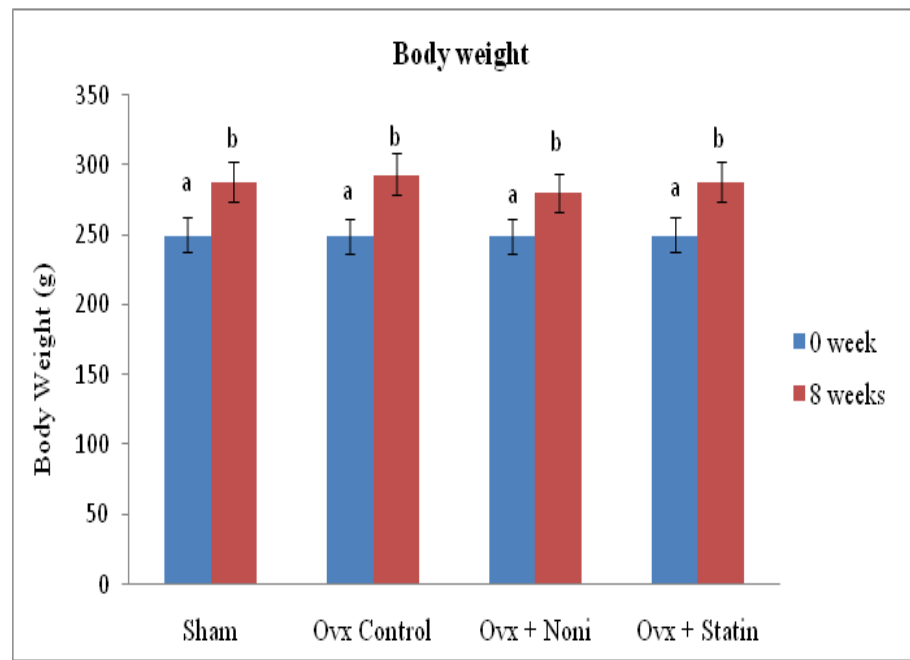

Figure I Effect of noni on body weight changes in ovariectomized rats fed with $2 \%$ cholesterol diet.

Values are given as mean \pm SD of six rats in each group. Values not sharing a common letter are significantly different among the groups $(p<0.05)$.

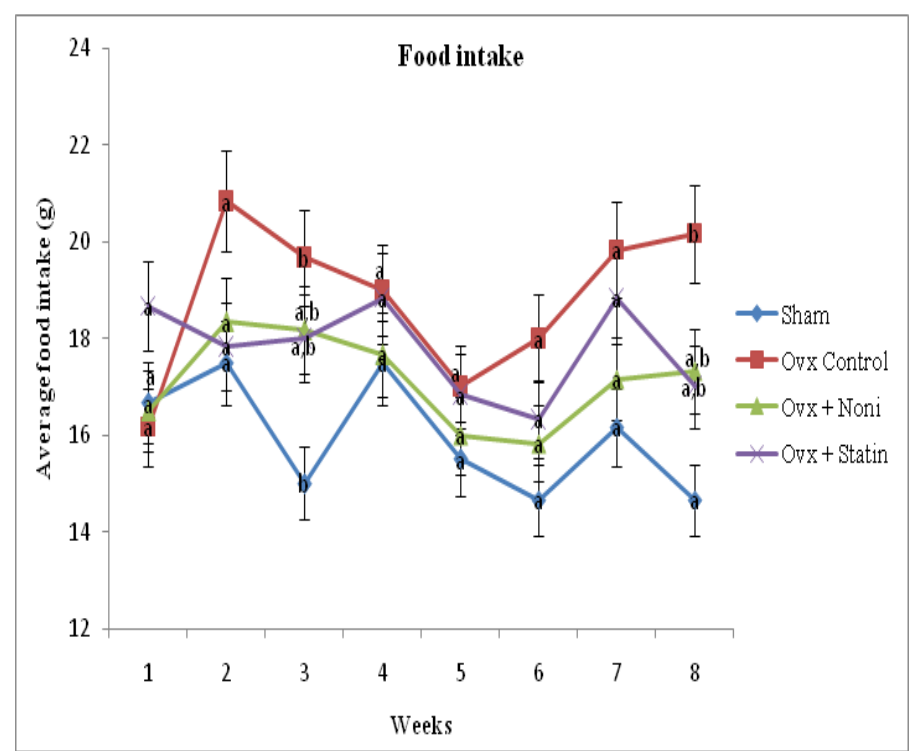

Figure 2 Effect of noni on average food intake in ovariectomized rats fed with $2 \%$ cholesterol diet.

Values are given as mean $\pm S D$ of six rats in each group. Values not sharing a common letter are significantly different among the groups $(p<0.05)$. 
The systolic blood pressure was measured in normal and cholesterol fed groups with Noni and Statin treated ovariectomized rats. The results were compared between the groups at the end of the study (i.e. at $8^{\text {th }}$ week of experimental period) (Figure 3A). It was observed that Ovx control group showed no significant increase in systolic blood pressure compared to sham group. No significant increase in systolic blood pressure was observed in the Noni and Statin treated animals when compared to Ovx control group. The diastolic blood pressure was measured in sham and cholesterol diet fed ovariectomized rats with Noni and Statin treated animals and the results were compared between the experimental groups at the end of the study (Figure 3B). It was observed that the Ovx control showed a significant $(\mathrm{p}<0.05)$ decrease in diastolic blood pressure compared to sham. Treatment with Noni and Statin in Ovx groups at the eighth week showed a significant $(\mathrm{p}<0.05)$ increase in the diastolic blood pressure when compared to Ovx control and sham groups. There was no significant difference in diastolic blood pressure observed between the Noni and Statin groups.

The mean arterial blood pressure was measured in sham and cholesterol diet fed ovariectomized rats with Noni and Statin treated animals and the results were compared between the groups at the end of the study (Figure 3C). It was observed that the Ovx control group had no significant difference in the mean blood pressure compared to the sham group. However, there was significant increase $(\mathrm{p}<0.05)$ in mean arterial pressure observed in the Noni and Statin groups compared to Ovx control.
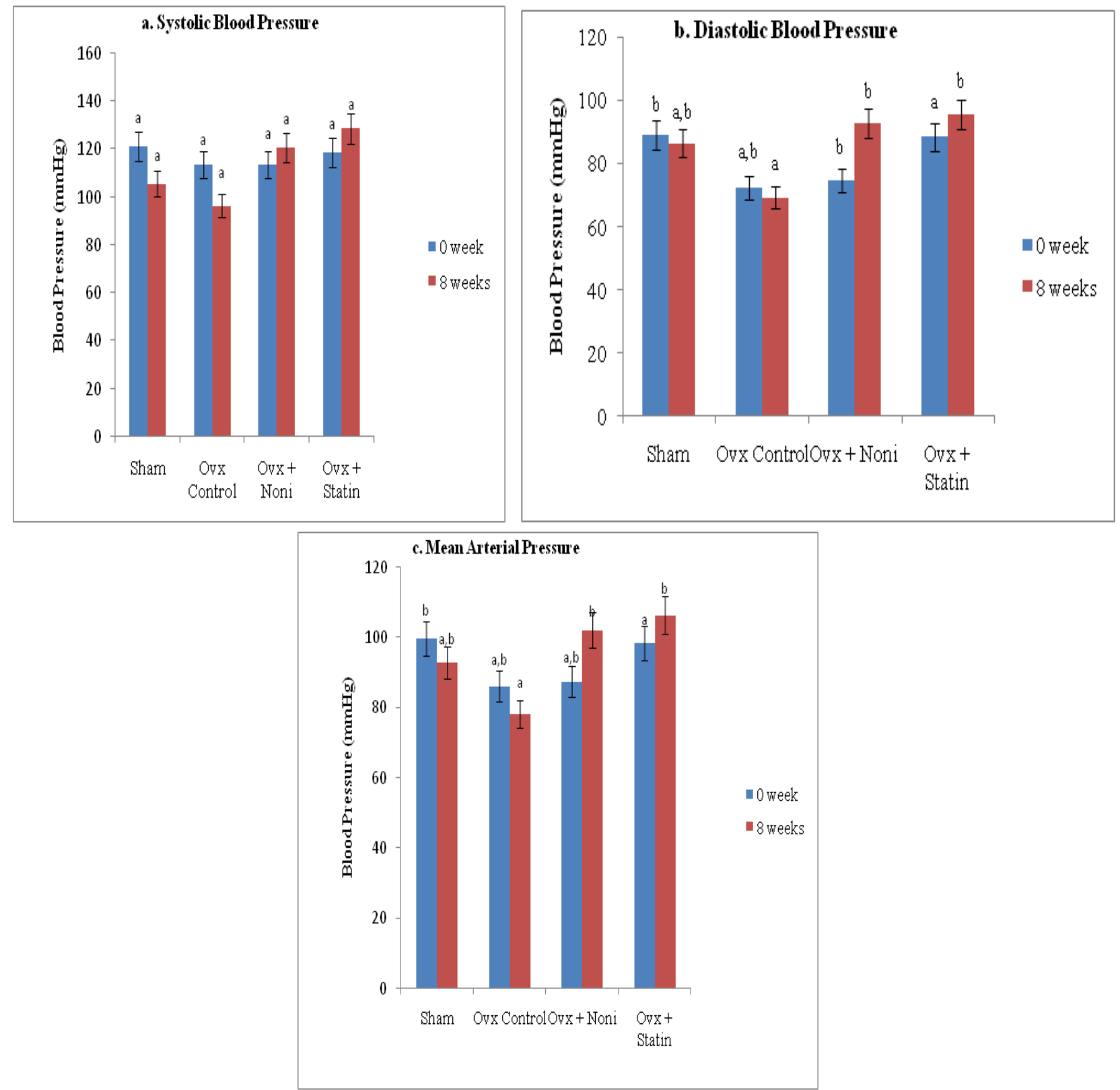

Figure 3 Effect of noni on blood pressure in ovariectomized rats fed with $2 \%$ cholesterol diet.

Values are given as mean \pm SD of six rats in each group.Values not sharing a common letter are significantly different among the groups $(p<0.05)$. 


\section{Discussion}

Several clinical and experimental studies had been carried out to investigate the complications that occur in postmenopausal states. Ovariectomized Sprague Dawley rats had been used as the model for postmenopausal states in human. ${ }^{33}$ Duration of the experimental period is worth studying to know the effects of cholesterol diet in short and long term periods. According to the literatures explored, short term period is presumed from 7 days to 4 weeks/less than 5 weeks and long term period is between 5-24 weeks of dietary cholesterol consumption. These durations are widely used in the atherosclerotic related cholesterol diet researches..$^{34,35}$

The present study used the ovariectomized rats to determine the effect of Noni, with Statin as its positive control on blood pressure, body weight and food intake following eight weeks of consumption of high fat diet containing $2 \%$ cholesterol. It was found that there was a significant increase in the body weight by the eighth week when compared to the base line values. No significant difference in the food intake in Ovx control group compared to sham group. The underlying mechanism related to the food intake and body weight changes in ovariectomized group fed with cholesterol is poorly understood. Yet, it was stated that cholesterol levels are strongly linked with the dietary intake. According to the literatures, individuals consuming more cholesterol in daily diet incline to have increased body weight compared to the individuals with normal diet. ${ }^{36}$ Our finding is in agreement with the previous study which reported that the significant increase in food intake was seen in the experimental rats within the first few weeks of ovariectomy. ${ }^{37}$ The increase in the body weight following gradual intake of food might most probably be due to the gradual reduction in lean body mass and progressive fat accumulation in different body regions. Progressive fat accumulation induces oxidative stress and was proven to cause obesity, hypertension and cardiovascular diseases. ${ }^{38}$ Previous study observed that weight gain in the ovariectomized rats was due to the oestrogen deficiency resulting in an increase in the fat accumulation. ${ }^{33}$ However, the findings are not in line with the present results which showed that Ovx group did not exhibit any significant increase in the body weight compared to the sham group. It can be explained that oestrogen has less influence on the body weight in early onset of postmenopausal state. Based on the present study, the increase in body weight mainly reflects the consumption of cholesterol diet. It is proven that the effect of oestrogen deficiency is further worsened with the additional cholesterol intake. Weight gain among the ovariectomized rats would probably happen with time.

Oestrogen deficiency causes a significant increase in the total cholesterol and triglycerides, which affects lipoprotein metabolism, platelet aggregation and vessel resistance. ${ }^{39}$ Previous studies observed that the intake of cholesterol-rich food develops obesity and several cardiovascular complications in various animal models. ${ }^{40,41}$ These high cholesterol diets induced damage to the endothelium of large arteries and heart causing hypertension and subsequently, producing atherosclerosis resulting in coronary heart disease..$^{42}$

In the present study, it is shown that there is no difference in the systolic, diastolic and mean blood pressure in the Ovx group. It was observed that consumption of additional $2 \%$ cholesterol diet for eight weeks caused no significant changes in the blood pressure measurement. The oestrogen deficiency following ovariectomy and increase cholesterol intake are the predisposing factors of the obesity. The incidence of hypertension frequently occurs in obese women with poor diet control, modern life style, existing family history and menopausal age. ${ }^{43}$ Therefore, it is most likely that ovariectomized rats fed with $2 \%$ cholesterol diet would develop hypertension. No significant changes were observed in the Ovx group was most likely due to its early onset of postmenopausal state. Oestrogen deficiency is believed to affect the physiological changes after prolonged onset. However, lack of oestrogen along with consumption of cholesterol diet may worsen the above findings even in the early onset.

In a routine research on cardiovascular disease, ovariectomized rats fed with $2 \%$ cholesterol had been used to develop the atherosclerotic animal model. The experiments related to this type of animal models are needed to be carried out for prolonged period (up to 24 weeks) ${ }^{34,35}$ in order to achieve the significant outcomes of atherosclerosis or hypertension. Based on the present findings, it is proven that the use of $2 \%$ cholesterol diet caused no such significant increase in food intake, body weight and blood pressure in ovariectomized rats over eight weeks (short term period) following ovariectomy.

\section{Conclusion}

Based on the observations, we concluded administration of Noni and Statin with the cholesterol diet for eight weeks (short term) resulted in significant increase in the food intake and body weight compared to base line, however there was no significant increase in the blood pressure of Ovx and experimental groups due to the short duration of the study.

\section{Acknowledgements}

We would like to acknowledge the Faculty of Medicine, University Kebangsaan Malaysia for their financial support by the NRGS Grant.

\section{Conflict of interest}

The author declares no conflict of interest.

\section{References}

1. Ng TP, Jin A, Chow KY, et al. Age-dependent relationships between body mass index and mortality: Singapore longitudinal ageing study. PLoS One. 2017;12(7):e0180818.

2. Bray GA. Risks of obesity. Endocrinol Metab Clin North Am. 2003;32(4):787-804.

3. Leong XF, Ng CY, Jaarin K. Animal Models in Cardiovascular Research: Hypertension and Atherosclerosis. Biomed Res Int. 2015;2015:528757.

4. Institute of Public Health (IPH). Ministry of Health Malaysia; 2008 2:199-316.

5. Green JS, Stanforth PR, Rankinen T, et al. The effects of exercise training on abdominal visceral fat, body composition, and indicators of the metabolic syndrome in postmenopausal women with and without estrogen replacement therapy: the HERITAGE family study. Metabolism. 2004;53(9):1192-1196.

6. Stefanick ML, Mackey S, Sheehan M, et al. Effects of diet and exercise in men and postmenopausal women with low levels of HDL cholesterol and high levels of LDL cholesterol. N Engl J Med. 1998;339(1):12-20.

7. Wang MY, West BJ, Jensen CJ, et al. Morinda citrifolia (Noni): a literature review and recent advances in Noni research. Acta Pharmacol Sin. 2002;23(12):1127-1141

8. Caramel S, Marchionni M, Stagnaro S. Morinda citrifolia plays a central role in the primary prevention of mitochondrial-dependent degenerative disorders. Asian Pac J Cancer Prev. 2015;16(4):1675. 
9. Hirazumi A, Furusawa E. An immunomodulatory polysaccharide-rich substance from the fruit juice of Morinda citrifolia (noni) with antitumour activity. Phytother Res. 1999;13(5):380-387.

10. Lim SL, Goh YM, Noordin MM, et al. Morinda citrifolia edible leaf extract enhanced immune response against lung cancer. Food Funct. 2016;7(2):741-751.

11. Nerurkar PV, Nishioka A, Eck PO, et al. Regulation of glucose metabolism via hepatic for khead transcription factor 1 (FoxO1) by $\mathrm{Mo}$ rinda citrifolia (noni) in high-fat diet-induced obese mice. Br J Nutr. 2012;108(2):218-228.

12. Pak-Dek MS, Abdul-Hamid A, Osman A, et al. Inhibitory effect of Morinda citrifolia L. On lipoprotein lipase activity. J Food Sci. 2008;73(8):C595-C598.

13. Candida T, Franca JP, Chaves AL, et al. Evaluation of antitumoral and antimicrobial activity of Morinda citrifolia L. grown in Southeast Brazil. Acta Cir Bras. 2014;29(Suppl 2):10-14.

14. Ahmed AS, Charles PD, Cholan R, et al. Antibacterial efficacy and effect of Morinda citrifolia L. mixed with irreversible hydrocolloid for dental impressions: a randomized controlled trial. J Pharm Bioallied Sci. 2015;7(Suppl 2):S597-S599.

15. Jainkittivong A, Butsarakamruha T, Langlais RP. Antifungal activity of Morinda citrifolia fruit extract against Candida albicans. Oral Surg Oral Med Oral Pathol Oral Radiol Endod. 2009;108(3):394-398.

16. Ratnoglik SL, Aoki C, Sudarmono P, et al. Antiviral activity of extracts from Morinda citrifolia leaves and chlorophyll catabolites, pheophorbide a and pyro pheophorbide a, against hepatitis C virus. Microbiol Immunol. 2014;58(3):188-194.

17. Almeida SF, Taniwaki NN, Amaral AC, et al. Ultrastructural changes and death of Leishmania infantum promastigotes induced by Morinda citrifolia Linn. Fruit (Noni) juice treatment. Evid Based Complement Alternat Med. 2016;2016:5063540.

18. Huang HL, Liu CT, Chou MC, et al. Noni (Morinda Citrifolia L.) Fruit Extracts Improve Colon Microflora and Exert Anti-Inflammatory Activities in Caco-2 Cells. J Med Food. 2015;18(6):663-676.

19. Okusada K, Nakamoto K, Nishida M, et al. The antinociceptive and anti-inflammatory action of the $\mathrm{CHCl}_{3}$-soluble phase and its main active component, damna canthal, isolated from the root of Morinda citrifolia. Biol Pharm Bull. 2011;34(1):103-107.

20. Kokturk S, Ceylan S, Etus V, et al. Morinda citrifolia L. (noni) and memantine attenuate periventricular tissue injury of the fourth ventricle in hydrocephalic rabbits. Neural Regen Res. 2013;8(9):773-782.

21. Palu A, Su C, Zhou BN, et al. Wound healing effects of noni (Morin da citrifolia L.) leaves: a mechanism involving its PDGF/ A2A receptor ligand binding and promotion of wound closure. Phytother Res. 2010;24(10):1437-1441.

22. Murata K, Abe Y, Futamura MM, et al. Activation of cell-mediated immunity by Morinda citrifolia fruit extract and its constituents. Nat Prod Commun. 2014;9(4):445-450.

23. Beh HK, Seow LJ, Asmawi MZ, et al. Anti-angiogenic activity of $\mathrm{Mo}$ rinda citrifolia extracts and its chemical constituents. Nat Prod Res. 2012;26(16):1492-1427.

24. Prapaitrakool S, Itharat A. Morinda citrifolia Linn. For prevention of postoperative nausea and vomiting. J Med Assoc Thai. 2010;93(Suppl 7):S204-S209.

25. Mahattanadul S, Ridtitid W, Nima S, et al. Effects of Morinda citrifolia aqueous fruit extract and its biomarker scopoletin on reflux esophagitis and gastric ulcer in rats. $J$ Ethnopharmacol. 2011;134(2):243-250.
26. Brito DR, Fernandes RM, Fernandes MZ, et al. Anthelmintic activity of aqueous and ethanolic extracts of Morinda citrifolia fruit on Ascaridia galli. Rev Bras Parasitol Vet. 2009;18(4):32-36.

27. Franchi LP, Guimaraes NN, De Andrade LR, et al. Antimutagenic and antirecombinagenic activities of noni fruit juice in somatic cells of Drosophila melanogaster. An Acad Bras Cienc. 2013;85(2):585-594.

28. Narasingam M, Pandy V, Mohamed Z. Noni (Morinda citrifolia L.) fruit extract attenuates the rewarding effect of heroin in conditioned place preference but not withdrawal in rodents. Exp Anim. 2016;65(2):157164

29. Kannan S, Manickam S, Rajamohammed MA. Anxiolytic, sedative and hypnotic activities of aqueous extract of Morinda citrifolia fruit. $J$ Ayurveda Integr Med. 2014;5(2):73-75.

30. West BJ, Deng S, Palu AK, et al. Morinda citrifolia Linn. (Rubiaceae) leaf extracts mitigate UVB-induced erythema. J Nat Med. 2009;63(3):351-354.

31. Kim SW, Jo BK, Jeong JH, et al. Induction of extracellular matrix synthesis in normal human fibroblasts by anthraquinone isolated from $\mathrm{Mo}$ rinda citrifolia (Noni) fruit. J Med Food. 2005;8(4):552-555.

32. Boonanantanasarn K, Janebodin K, Suppakpatana P, et al. Morinda citrifolia leaves enhance osteogenic differentiation and mineralization of human periodontal ligament cells. Dent Mater J. 2014;33(2):157165 .

33. Latour MG, Shinoda M, Lavoie JM. Metabolic effects of physical training in ovariectomized and hyperestrogenic rats. J Appl Physiol. 2001;90(1):235-241.

34. Lichtenstein AH, Ausman LM, Carrasco W, et al. Short-term consumption of a low-fat diet beneficially affects plasma lipid concentrations only when accompanied by weight loss. Hypercholesterolemia, low-fat diet, and plasma lipids. Arterioscler Thromb. 1994;14(11):1751-1760.

35. Brown SA, Morrisett J, Patsch JR, et al. Influence of short term dietary cholesterol and fat on human plasma Lp[a] and LDL levels. J Lipid Res. 1991;32(8):1281-1289.

36. Kresser C. The Diet-Heart Myth: Cholesterol and Saturated Fat Are Not the Enemy. 2013.

37. McElroy JF, Wade GN. Short- and long-term effects of ovariectomy on food intake, body weight, carcass composition, and brown adipose tissue in rats. Physiol Behav. 1987;39(3):361-365.

38. Park SJ, Yang HM, Seo KW, et al. The relationship between coronary atherosclerosis and body fat distribution measured using dual energy X-ray absorptiometry. Atherosclerosis. 2016;248:190-195.

39. Gorodeski EZ, Gorodeski GI. Epidemiology and risk factors of cardiovascular disease in post menopausal woman. In: Lobo RA, editor. Treatment of the Postmenopausal Woman: Basic and Clinical Aspects. 3rd ed. USA: Elsevier; 2007. p. 405-452.

40. Kennedy AJ, Ellacott KL, King VL, et al. Mouse models of the metabolic syndrome. Dis Model Mech. 2010;3(3-4):156-166.

41. Ali M, Al-Qattan KK, Al-Enezi F, et al. Effect of allicin from garlic powder on serum lipids and blood pressure in rats fed with a high cholesterol diet. Prostaglandins Leukot Essent Fatty Acids. 2000;62(4):253-259.

42. Ryou SH, Kang MS, Kim KI, et al. Effects of green tea or Sasa quelpaertensis bamboo leaves on plasma and liver lipids, erythrocyte $\mathrm{Na}$ efflux, and platelet aggregation in ovariectomized rats. Nutr Res Pract. 2012;6(2):106-112.

43. American Heart Association. Heart Disease and Stroke Statistics. USA 2008 